\title{
Medium Optimization for Pediocin SA131 Production by Pediococcus pentosaceus SA131 against Bovine Mastitis Using Response Surface Methodology
}

\author{
Yeo-Lang Park, Na-Kyoung Lee, Keun-Kyu Park ${ }^{1}$, Yongho Park², Jong-Man Kim³, \\ Hyang-Mi Nam ${ }^{3}$, Suk-Chan Jung ${ }^{3}$, and Hyun-Dong Paik* \\ Division of Animal Life Science, Konkuk University, Seoul 143-701, Korea \\ ${ }^{1}$ Animal Resources Research Center, Konkuk University, Seoul 143-701, Korea \\ ${ }^{2}$ College of Veterinary Medicine, Seoul National University, Seoul 157-142, Korea \\ ${ }^{3}$ National Veterinary Research \& Quarantine Service, Anyang 430-824, Korea
}

\begin{abstract}
Pediococcus pentosaceus SA131 was isolated from jeotgal, is the bacteriocin producer against bovine mastitis pathogens, Streptococcus uberis E290, Enterococcus gallinarum E362, and Staphylococcus epidermidis ATCC 12228. The medium composition for pediocin SA131 production by $P$. pentosaceus SA131 was optimized using response surface methodology. Component of medium was studied as carbon source (glucose, fructose, lactose, glycerol, sucrose, maltose, and mannitol), nitrogen source (beef extract, yeast extract, peptone, malt extract, and tryptone), mineral and surfactant $\left(\mathrm{MgSO}_{4}, \mathrm{KH}_{2} \mathrm{PO}_{4}\right.$, $\left(\mathrm{NH}_{4}\right)_{2} \mathrm{SO}_{4}, \mathrm{MnSO}_{4}, \mathrm{NaCl}$, sodium acetate, and Tween 80). Through one factor-at-a-time experiment, glucose, fructose, yeast extract, malt extract, $\mathrm{NaCl}, \mathrm{MgSO}_{4}$, and Tween 80 were determined as the good ingredient. The effects of major factors for pediocin SA131 production were investigated by two-level fractional factorial designs (FFD). By a $2^{4}$ FFD, fructose, yeast extract, and $\mathrm{MnSO}_{4}$ were found to be the important factors for the bacteriocin production. Subsequently, a $2^{3}$ central composite design (CCD) was adopted to derive a statistical model for optimizing the composition of the fermentation medium. The estimated optimum composition for the production of pediocin SA131 by P. pentosaceus SA131 was as follows; $0.13 \%$ fructose, $1 \%$ glucose, $1.8 \%$ yeast extract, $2.58 \% \mathrm{MnSO}_{4}, 0.2 \% \mathrm{NaCl}$, and $0.2 \%$ Tween 80 . The pediocin production under optimized medium was increased to $1,000 \mathrm{AU} / \mathrm{mL}$, compared to the $400 \mathrm{AU} / \mathrm{mL}$ in $\mathrm{MRS}$ medium.
\end{abstract}

Key words: Pediococcus pentosaceus SA131, bacteriocin, pediocin SA131, medium optimization, bovine mastitis, response surface methodology

\section{Introduction}

Bovine mastitis is an inflammation of the mammary glands due to a microbial infection and is one of the most important causes of economic losses to the dairy industry due to rejected milk, degraded milk quality, and drug costs (Nascimento et al., 2005). Although several bacterial pathogens can cause bovine mastitis, Staphylococcus spp. and Streptococcus spp. are the major causative agents and it is difficult to eradicate (Coelho et al., 2007; Ochoa-Zarzosa et al., 2008).

The treatment of mastitis makes use of antimicrobial

*Corresponding author : Hyun-Dong Paik, Division of Animal Life Science, Konkuk University, Seoul 143-701, Korea. Tel: 82-2-2049-6011, Fax: 82-2-455-3082, E-mail: hdpaik@konkuk. ac.kr substances. These methods include management of immediate release procedures during lactation or longacting procedures during the non-lactating period. Most of drugs have been utilized for non-lactating cow therapy. This treatment is considered inadequate because of limited success, cure rates vary considerably. In addition, public authorities advise careful use of antibiotics as their use that may promote bacterial antibiotic resistance and leave antibiotic residues in the food chain. Moreover, it has been verified that the indiscriminate treatment with antibiotics, without either a technical prescription or identification tests of the pathogen, can contribute to an increased resistance of their microorganisms, making the cure of mastitis more difficult. Thus, the alternative methods for controlling mastitis are necessary and one of these methods could be the use of bacteriocins (Coelho et al., 2007). 
Bacteriocins are antimicrobial peptides produced by various lactic acid bacteria (LAB) including lactobacilli, lactococci, leuconostoc, and pediococci (Choi et al., 2000). LAB have been utilized as starter strains, probiotics, foods, and feed additives for therapeutic, prophylactic acid growth promotion in animal. Therefore, bacteriocins produced by LAB have presented a potential use either in food industries as biopreservatives or in the prevention and treatment of some infectious diseases, having medical and veterinary applications. Nisin from Lactococcus lactis is representative bacteriocin, has activity against mastitis and has been widely used as a food preservative in many countries (Barboza-Corona et al., 2009). The staphylococcal bacteriocins showed antibacterial activity against Staphylococcus aureus and Streptococcus agalactiae involved in bovine mastitis (Coelho et al., 2007). Also, lacticin NK34 was indentified as a bacteriocin having inhibitory activity against mastitis (Lee et al., 2008).

The production of bacteriocins is influenced by bacterial growth because bacteriocins are synthesized during the growth of the producing organism. Bacteriocin production is also affected by the medium compositions such as carbon sources, nitrogen sources, growth factors, and inorganic salts. Therefore, the medium compositions are very important for the optimization of bacteriocin production. It is difficult to search for the major factors and to optimize them for biotechnological processes including multivariable. For optimizing multivariables, the classical 'one factor-at-a time' method has utilized. This method involves changing independent variable while fixing all others at a fixed level. However, it is extremely time-consuming and expensive for a large number of variables and also may result in wrong conclusions. One of the valuable techniques to identify the explanatory variable in the system is response surface methodology (RSM). This is a collection of statistical techniques for designing experiments, building models, evaluation the effects of factors, and searching optimal conditions of factors for desirable response (Cheigh et al., 2002; Delgado et al., 2007; He et al., 2004; Li et al., 2002).

The aim of this study was to optimize culture medium for maximum production of pediocin SA131 using RSM.

\section{Materials and Methods}

\section{Bacterial strains and culture media}

P. pentosaceus SA131 was isolated from jeotgal, cultured in lactobacilli MRS medium (Difco Laboratories, Detroit, MI, USA) at $35^{\circ} \mathrm{C}$. The indicator strain was Sta- phylococcus epidermidis ATCC 12228. S. epidermidis ATCC 12228 was cultured in tryptic soy broth (TSB, Difco) at $35^{\circ} \mathrm{C}$. These strains were stored at $-70^{\circ} \mathrm{C}$ in medium with $20 \%$ (v/v) glycerol.

\section{Antimicrobial activity assay}

Pediocin SA131 activity was determined by the spoton-lawn method (Lee et al., 2008). Soft MRS agar seeded $(1 \%, \mathrm{v} / \mathrm{v})$ with the indicator microorganisms (ca. 10 $\mathrm{CFU}$ ) was overlayed on the plate, and was solidified. Bacteriocin solution was diluted serially using two-fold dilution, and $10 \mu \mathrm{L}$ of each dilution was spotted on the plate. The plates were incubated at $35^{\circ} \mathrm{C}$ overnight. The bacteriocin activity was determined as arbitrary unit (AU) as follow; Bacteriocin activity $(\mathrm{AU} / \mathrm{mL})=2^{\mathrm{N}} \times 100$, where $\mathrm{N}=$ dilution number with the smallest zone of inhibition.

\section{Selection of the best medium for bacteriocin pro- duction}

Carbon, nitrogen source, mineral and surfactant for selection of the best source have been screened by one factor-at-a time method. Firstly, for selection of carbon source, $1 \%(\mathrm{w} / \mathrm{v})$ carbon source (glucose, fructose, lactose, glycerol, sucrose, maltose, and mannitol) was added in $200 \mathrm{~mL}$ flask containing $100 \mathrm{~mL}$ of medium with $1 \%$ yeast extract. After selection of carbon source, the cultivation medium with $1 \%(\mathrm{w} / \mathrm{v})$ nitrogen source (beef extract, yeast extract, peptone, malt extract, and tryptone) and $1 \%$ fructose was cultured. Subsequently, the medium with mineral and surfactant $\left(\mathrm{MgSO}_{4}, \mathrm{KH}_{2} \mathrm{PO}_{4},\left(\mathrm{NH}_{4}\right)_{2} \mathrm{SO}_{4}\right.$, $\mathrm{MnSO}_{4}, \mathrm{NaCl}$, sodium acetate, and Tween 80) and $1 \%$ fructose and yeast extract was cultured. Cultivation was performed for $20 \mathrm{~h}$ of incubation at $35^{\circ} \mathrm{C}$. The number of viable cells of the culture was determined as colony forming unit (CFU) and antimicrobial activity (AU/mL) of pediocin SA131 was observed after $20 \mathrm{~h}$.

\section{Fractional factorial design}

Seven variables affecting production of pediocin SA131 were selected by one factor-at-a time method. The variables having significant effects were identified using a fractional factorial design (FFD). This method is very useful in identifying the important compounds and interactions between two and more nutrients in few experiments (Kim et al, 2004; Wang and Liu, 2008). FFD at the given range of the above parameters in terms of coded and actual values is presented in Table 1 . A $2^{4}$ FFD with seven factors at two levels, $2^{4}=16$ runs and four runs were center point runs for statistical reasons. Data analy- 
Table 1. The concentration of variables of different levels of the $2^{4}$ fractional factorial design $(\%, w / v)$

\begin{tabular}{cllll}
\hline \hline \multirow{2}{*}{$\begin{array}{c}\text { Variable } \\
\text { code }\end{array}$} & $\begin{array}{c}\text { Independent } \\
\text { variables }\end{array}$ & \multicolumn{3}{c}{ Levels } \\
\cline { 3 - 5 } & & \multicolumn{1}{c}{-1} & \multicolumn{1}{c}{0} & \multicolumn{1}{c}{1} \\
\hline $\mathrm{X}_{1}$ & Fructose & 0 & 0.5 & 1 \\
$\mathrm{X}_{2}$ & Glucose & 0.5 & 1 & 1.5 \\
$\mathrm{X}_{3}$ & Yeast extract & 0.5 & 1 & 1.5 \\
$\mathrm{X}_{4}$ & Malt extract & 0 & 0.5 & 1 \\
$\mathrm{X}_{5}$ & $\mathrm{NaCl}$ & 0.1 & 0.2 & 0.3 \\
$\mathrm{X}_{6}$ & $\mathrm{MnSO}_{4}$ & 0 & 0.1 & 0.2 \\
$\mathrm{X}_{7}$ & Tween 80 & 0.1 & 0.2 & 0.3 \\
\hline
\end{tabular}

sis was generated by the software SAS (Statistical Analysis Program, version 9.1). The major effects of variables on bacteriocin production were identified for the isolates on the basis of confidence levels above 95\% $(p<0.05)$. From the FFD experimental results, a first-order model was represented by;

$$
Y=\Sigma a_{i} x_{i}+c_{o}+\varepsilon
$$

Where $Y$ is the predicted response (bacteriocin activity). The parameters $a_{\mathrm{i}}$ are functions of $x_{i}, c_{o}$ is the intercept term and the remaining term, $\varepsilon$, represents random errors in the yield values.

\section{Central composite design and statistical analysis}

To describe the nature of the response surface in the optimum region, a $2^{3}$ factorial central composite design (CCD) was performed. CCD with six star points $(\alpha=2)$ and three replications of the central points was used at five levels. The levels for each factor are given in Table 4. For predicting the optimal point, a second-order polynomial function was;

$$
Y=c_{0}+\sum_{i=1}^{n} a_{i} x_{i}+\sum_{j \leq i}^{n} b_{i j} x_{i} x_{j}
$$

Where $Y$, predicted response, stands for bacteriocin activity (AU/mL). Subscripts $i$ and $j$ takes values from 1 to the number of variables $(n)$; the $c_{o}$ is the intercept term; the $\mathrm{a}_{\mathrm{i}}$ values are linear coefficient; the $b_{i j}$ values are quadratic coefficients; $x_{i}$ and $x_{j}$ are the level of the independent variables (Liu and Tzeng, 1998; Purama and Goyal, 2008). The data analysis was generated by the software SAS (Statistical Analysis Program, version 9.1).

\section{Results and Discussion}

\section{Pediocin SA131 production in MRS broth}

The growth of P. pentosaceus SA131 and the production of pediocin SA131 were observed in MRS broth at $35^{\circ} \mathrm{C}$ for $24 \mathrm{~h}$ (Fig. 1). The cells reached stationary phase after $18 \mathrm{~h}$ of fermentation and the number of viable cell was 9.46 Log CFU/mL. The production of pediocin SA131 approximately followed the growth curve and increased to $400 \mathrm{AU} / \mathrm{mL}$ during the exponential phase of growth and remained at this level throughout the stationary phase. For selection of the best components, one factor-at-a time method was taken by $20 \mathrm{~h}$ of incubation at $35^{\circ} \mathrm{C}$.

\section{Effect of different source in cell growth and pedio- cin SA131 production}

The effect of carbon source was studied using medium with $1 \%(\mathrm{w} / \mathrm{v})$ different carbon source (glucose, fructose, lactose, glycerol, sucrose, maltose, and mannitol) and $1 \%$ yeast extract. As shown in Fig. 2A, P. pentosaceus SA131 in media contained gluocose or fructose showed the high bacteriocin activity of pediocin SA131. At 1\%(w/v) concentration of carbon source, the bacteriocin activity was 40 and $80 \mathrm{AU} / \mathrm{mL}$ for glucose and fructose, respectively. However, maximum growth was observed in $1 \%$ sucrose. Accordingly, glucose and fructose were selected as the potential carbon source for production of pediocin SA131. It was also reported to be suitable carbon source for pediocin SA131 production by P. acidilactici NRRL B5627 (Anastasiadou et al., 2008).

In order to assess the influence of different nitrogen source on bacteriocin production, the cultivation medium with $1 \%(\mathrm{w} / \mathrm{v})$ nitrogen source (beef extract, yeast extract, peptone, malt extract, and tryptone) and $1 \%$ fructose was cultured. As shown in Fig. 2B, the bacteriocin activity in the medium contained $1 \%$ yeast extract or $1 \%$ malt extract was higher than others. Yeast extract played an important role on the production of the bacteriocin. Due to the use of larger quantity of free amino acids, short peptides and more growth factors from yeast extract that induced bacteriocin production (Anthony et al., 2009; Cheigh et al., 2002; Kim et al., 2006).

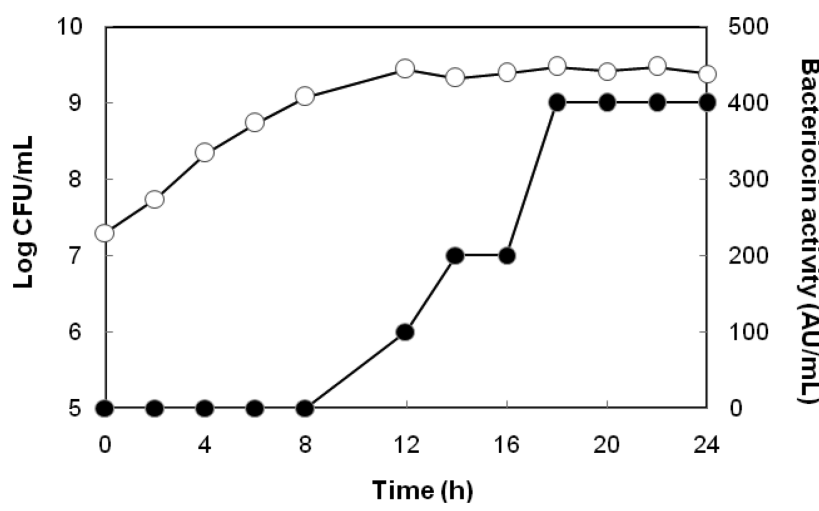

Fig. 1. Growth of $P$. pentosaceus SA131 ( $O$ ) and production of pediocin SA131 ( $)$ in MRS broth. 

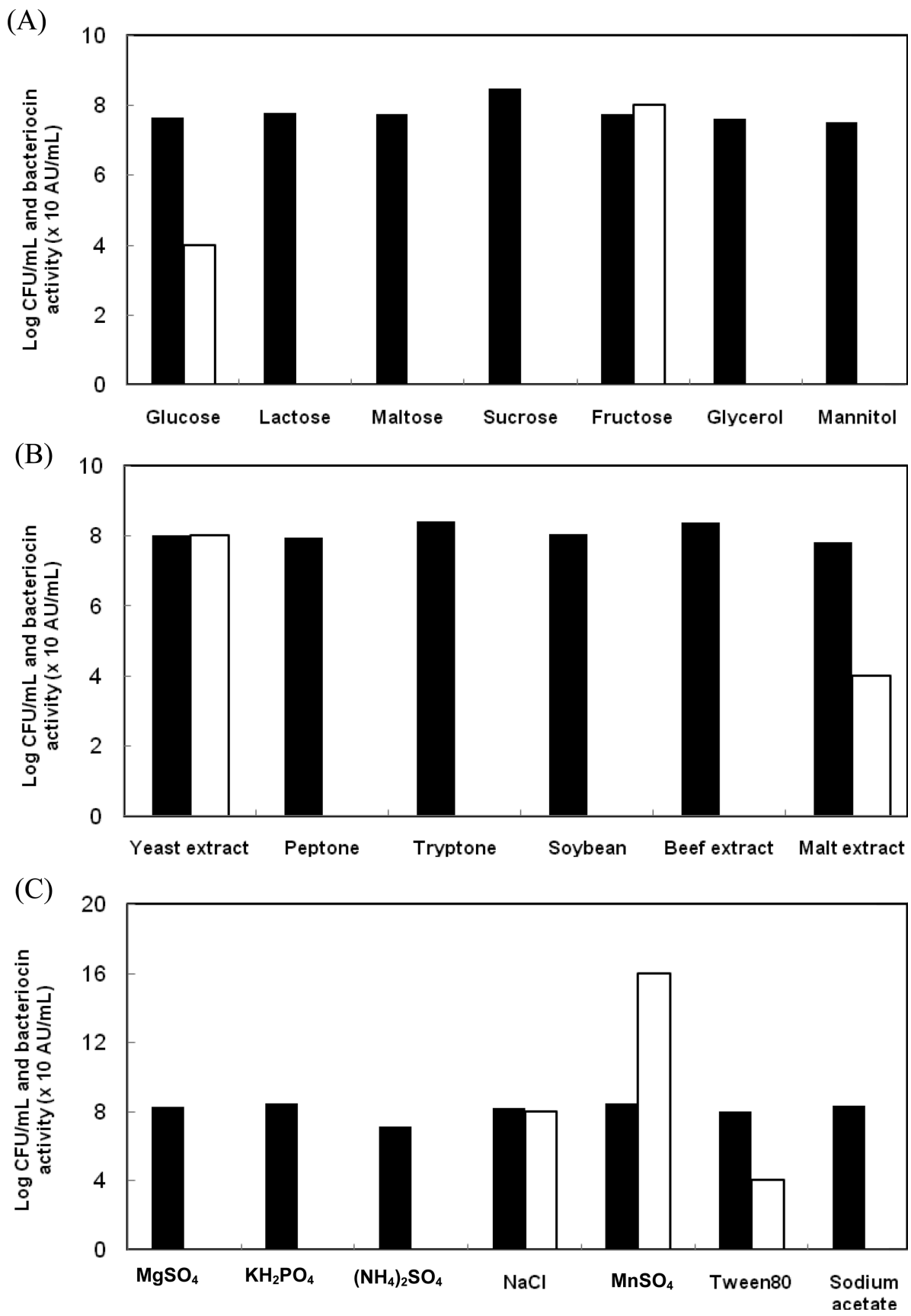

Fig. 2. Effect of different sources on the growth ( $\square$ ) and production of pediocin SA131 ( $\square$ ) at $20 \mathrm{~h}$. (A) effect of carbon sources, (B) effect of nitrogen sources, (C) effect of minerals and surfactants.

The effect of mineral and surfactant was tested using medium with $0.2 \%(\mathrm{w} / \mathrm{v})$ mineral and surfactant $\left(\mathrm{MgSO}_{4}\right.$, $\mathrm{KH}_{2} \mathrm{PO}_{4},\left(\mathrm{NH}_{4}\right)_{2} \mathrm{SO}_{4}, \mathrm{MnSO}_{4}, \mathrm{NaCl}$, sodium acetate, and Tween 80 ), $1 \%$ fructose and $1 \%$ yeast extract. As shown in Fig. 2C, pediocin SA131 activity was observed in $\mathrm{MnSO}_{4}, \mathrm{NaCl}$, and Tween 80. An increase in $\mathrm{MnSO}_{4}$ and Tween 80 concentration results in the increase of plantaricin 423 (Verellen et al., 1998) and pediocin PD-1 (Nel et al., 2001). Therefore, seven variables (glucose, fructose, yeast extract, malt extract, $\mathrm{MnSO}_{4}, \mathrm{NaCl}$, and Tween 80) supposed to affect pediocin SA131 production were selected for the two-level FFD.

\section{Optimization for pediocin SA131 production by FFD}

A two-level FFD was employed and Table 2 shows the seven independent variables and their concentrations at the different coded levels of the FFD and the corresponding response. The corresponding first-order model equation fitted to the experimental data has the formula; 
Table 2. Experimental design and results of $2^{4}$ fractional factorial design

\begin{tabular}{rrrrrrrrc}
\hline \hline Run & $\mathrm{X}_{1}$ & $\mathrm{X}_{2}$ & $\mathrm{X}_{3}$ & $\mathrm{X}_{4}$ & $\mathrm{X}_{5}$ & $\mathrm{X}_{6}$ & $\mathrm{X}_{7}$ & $\begin{array}{c}\text { Bacteriocin } \\
\text { activity }(\mathrm{AU} / \mathrm{mL})\end{array}$ \\
\hline 1 & -1 & -1 & -1 & -1 & -1 & -1 & -1 & 0 \\
2 & 1 & -1 & -1 & -1 & 1 & 1 & 1 & 200 \\
3 & -1 & 1 & -1 & -1 & 1 & 1 & -1 & 300 \\
4 & 1 & 1 & -1 & -1 & -1 & -1 & 1 & 0 \\
5 & -1 & -1 & 1 & -1 & 1 & -1 & 1 & 300 \\
6 & 1 & -1 & 1 & -1 & -1 & 1 & -1 & 300 \\
7 & -1 & 1 & 1 & -1 & -1 & 1 & 1 & 600 \\
8 & 1 & 1 & 1 & -1 & 1 & -1 & -1 & 200 \\
9 & -1 & -1 & -1 & 1 & -1 & 1 & 1 & 200 \\
10 & 1 & -1 & -1 & 1 & 1 & -1 & -1 & 0 \\
11 & -1 & 1 & -1 & 1 & 1 & -1 & 1 & 0 \\
12 & 1 & 1 & -1 & 1 & -1 & 1 & -1 & 0 \\
13 & -1 & -1 & 1 & 1 & 1 & 1 & -1 & 200 \\
14 & 1 & -1 & 1 & 1 & -1 & -1 & 1 & 0 \\
15 & -1 & 1 & 1 & 1 & -1 & -1 & -1 & 0 \\
16 & 1 & 1 & 1 & 1 & 1 & 1 & 1 & 150 \\
17 & 0 & 0 & 0 & 0 & 0 & 0 & 0 & 100 \\
18 & 0 & 0 & 0 & 0 & 0 & 0 & 0 & 100 \\
19 & 0 & 0 & 0 & 0 & 0 & 0 & 0 & 100 \\
20 & 0 & 0 & 0 & 0 & 0 & 0 & 0 & 100 \\
\hline
\end{tabular}

$$
\begin{aligned}
Y= & -41.87-93.75 X_{1}+6.25 X_{2}+131.25 X_{3}-168.75 X_{4} \\
& +156.25 X_{5}+906.25 X_{6}+281.25 X_{7}
\end{aligned}
$$

From Eq. (3), $\mathrm{MnSO}_{4}\left(\mathrm{X}_{6}\right)$ was shown to be the most significant factor for pediocin SA131 production. Manganese have roles as constituents of important enzymes involved in glucose hydrolysis and oxidative stress response in lactic acid bacteria (Coenye and Vandamme, 2003; Miyoshi et al., 2003). A main protective role of manganese ions from oxidation is expected to enhance overall culture productivity. In addition, an improved glucose conversion rate in the presence of manganese should be expected to increase the flux towards end-products synthesis in the metabolic machinery of Pediococcus (Anastasiadou et al., 2008). Regression analysis of the FFD in Table 3 presented fructose, yeast extract, malt extract, and $\mathrm{MnSO}_{4}$ were significant at the probability levels of $95 \%$ and proved to be the most important components. Glucose, $\mathrm{NaCl}$, and Tween 80 were not found to be statistically significant.

\section{Optimization for pediocin SA131 production by steepest ascent path}

Steepest ascent method utilizes the magnitude and sign of the linear effects to determine the direction toward a predictive higher response. The path begins at the center
Table 3. Results of the FFD regression analysis for bacteriocin activity

\begin{tabular}{cccc}
\hline \hline Term & Coefficient & t-Value & Significant level \\
\hline Intercept & -41.87 & -0.46 & 0.6536 \\
$\mathrm{X}_{1}$ & -93.75 & -2.29 & $0.0408^{\mathrm{a}}$ \\
$\mathrm{X}_{2}$ & 6.25 & 0.15 & 0.8811 \\
$\mathrm{X}_{3}$ & 131.25 & 3.21 & $0.0075^{\mathrm{a}}$ \\
$\mathrm{X}_{4}$ & -168.75 & -4.13 & $0.0014^{\mathrm{a}}$ \\
$\mathrm{X}_{5}$ & 156.25 & 0.76 & 0.4596 \\
$\mathrm{X}_{6}$ & 906.25 & 4.43 & $0.0008^{\mathrm{b}}$ \\
$\mathrm{X}_{7}$ & 281.25 & 1.38 & 0.1941 \\
\hline
\end{tabular}

${ }^{\text {a }}$ Significant at $5 \%$ level.

${ }^{\mathrm{b}}$ Significant at $1 \%$ level.

of the current design space and stretched well outside the design space. The path of steepest ascent was determined by Eq. (3) and regression analysis for pediocin SA131 production. Glucose $\left(\mathrm{X}_{2}\right), \mathrm{NaCl}\left(\mathrm{X}_{4}\right)$ and Tween $80\left(\mathrm{X}_{7}\right)$ were fixed at the center level of the FFD because they were not significant at the probability level of $95 \%$ for pediocin SA131 production. For four significant factors, increasing the concentration of yeast extract $\left(\mathrm{X}_{3}\right), \mathrm{MnSO}_{4}$ $\left(X_{5}\right)$ and decreasing the concentration of fructose $\left(X_{1}\right)$, malt extract $\left(\mathrm{X}_{4}\right)$ according to the signs of their main effects should have a positive consequence for pediocin SA131 production by $P$. pentosaceus SA131. The highest pediocin SA131 production was achieved with $0.2 \%$ fructose, $1.42 \%$ yeast extract, $3.1 \% \mathrm{MnSO}_{4}$ and this medium was chosen for the further optimization (data not shown).

\section{Optimization for pediocin SA131 production by RSM}

The central composite design, with five settings for three factors (fructose, yeast extract, and $\mathrm{MnSO}_{4}$ ) was run to optimize the process. The experimental design and results of ANOVA for the 17 trials are presented in Tables 4 and 5. Corresponding second-order response model for Eq. (2) that was found after SAS RSREG analysis for the regression is presented below;

$$
\begin{aligned}
Y= & 5013-2246.43 X_{1}+1645.60 X_{2}-3475.71 X_{3} \\
& +4004.34 X_{1}^{2}-90 X_{1} X_{2}-139.82 X_{2}^{2}+150 X_{1} X_{3} \\
& -350 X_{2} X_{3}+628 X_{3}^{2}
\end{aligned}
$$

Statistical significance of the second-order model equation was checked by $F$-test. The fit of model was presented by the coefficient of determination $\mathrm{R}^{2}$, which was found to be 0.87 , indicating $87 \%$ of the variability in the response can be explained by the model. The two dimensional contour plot is generally the graphical representa- 
Table 4. The central composite design of three variables in real and coded units (parenthesis) and the response of bacteriocin activity

\begin{tabular}{|c|c|c|c|c|}
\hline Run & $\begin{array}{l}\text { Fructose } \\
\left(\mathrm{X}_{1}\right)\end{array}$ & $\begin{array}{c}\text { Yeast extract } \\
\left(\mathrm{X}_{2}\right)\end{array}$ & $\begin{array}{c}\mathrm{MnSO}_{4} \\
\left(\mathrm{X}_{3}\right) \\
\end{array}$ & $\begin{array}{c}\text { Bacteriocin } \\
\text { activity }(\mathrm{AU} / \mathrm{mL})\end{array}$ \\
\hline 1 & $0.1 \quad(-1)$ & $0.92(-1)$ & $2.8(-1)$ & 572 \\
\hline 2 & 0.3 & $0.92 \quad(-1)$ & $2.8(-1)$ & 572 \\
\hline 3 & $0.1 \quad(-1)$ & 1.92 (1) & $2.8(-1)$ & 800 \\
\hline 4 & 0.3 & 1.92 (1) & $2.8(-1)$ & 668 \\
\hline 5 & $0.1 \quad(-1)$ & $0.92(-1)$ & 3.4 & 668 \\
\hline 6 & 0.3 & $0.92 \quad(-1)$ & 3.4 (1) & 572 \\
\hline 7 & $0.1 \quad(-1)$ & $1.92 \quad(1)$ & 3.4 & 572 \\
\hline 8 & 0.3 & $1.92 \quad(1)$ & 3.4 (1) & 572 \\
\hline 9 & $0.0 \quad(-2)$ & $1.42(0)$ & $3.1(0)$ & 800 \\
\hline 10 & 0.4 & $1.42(0)$ & $3.1(0)$ & 668 \\
\hline 11 & $0.2 \quad(0)$ & $0.42 \quad(-2)$ & 3.1 & 200 \\
\hline 12 & $0.2 \quad(0)$ & $2.42 \quad(2)$ & $3.1(0)$ & 668 \\
\hline 13 & $0.2 \quad(0)$ & $1.42(0)$ & $2.5(-2)$ & 800 \\
\hline 14 & $0.2 \quad(0)$ & $1.42(0)$ & 3.7 (2) & 800 \\
\hline 15 & $0.2 \quad(0)$ & $1.42(0)$ & $3.1(0)$ & 572 \\
\hline 16 & $0.2 \quad(0)$ & $1.42(0)$ & $3.1(0)$ & 572 \\
\hline 17 & $0.2 \quad(0)$ & $1.42(0)$ & $3.1(0)$ & 572 \\
\hline
\end{tabular}

$\mathrm{X}_{1}, \mathrm{X}_{2}$, and $\mathrm{X}_{3}$ are mentioned in $\%, \mathrm{w} / \mathrm{v}$.

Table 5. ANOVA results for central composite design

\begin{tabular}{lrrrrr}
\hline \hline \multirow{2}{*}{ Regression } & $\mathrm{DF}^{1)} \begin{array}{c}\text { Type sum of } \\
\text { squares }\end{array}$ & $R$-square & $F$-value & $P>F$ \\
\hline Linear & 3 & 103059 & 0.3095 & 5.78 & 0.0262 \\
Quadratic & 3 & 165912 & 0.4983 & 9.30 & 0.0077 \\
Crossproduct & 3 & 22374 & 0.0672 & 1.25 & 0.3608 \\
Total model & 9 & 291345 & 0.8750 & 5.44 & 0.0180 \\
\hline
\end{tabular}

${ }^{1)} \mathrm{DF}$ : Degree of freedom.

tion of the regression equation and it is easy to understand the interaction between two nutrients (Fig. 3). Fig. 3A describes the combined effects for fructose and yeast extract. An increase in pediocin SA131 production could be significantly achieved with the increase of yeast extract. The two dimensional contour plot of the combined effects of yeast extract and $\mathrm{MnSO}_{4}$ on the pediocin SA131 production was shown in Fig. 3B. It was evident from the calculated response surface that pediocin SA131 activity $(\mathrm{AU} / \mathrm{mL})$ reached its maximum at a concentration of coded level; $0.13 \%$ fructose, $1.8 \%$ yeast extract, $2.58 \% \mathrm{MnSO}_{4}$. The model predicted a maximum response of $911 \mathrm{AU} / \mathrm{mL}$ for this point. To confirm these results, experiments using the maximum point were performed and a value of $1,000 \mathrm{AU} / \mathrm{mL}$ was obtained. This value also was about doubled than that in MRS medium. The good correlation between these two results confirmed the validity of response model and the model was proven to be adequate.


Fig. 3. Contour plot of pediocin SA131 production. (A) effect of fructose and yeast extract, (B) effect of yeast extract and $\mathrm{MnSO}_{4}$.

\section{Acknowledgements}

This study was funded by a research grant from National Veterinary Research \& Quarantine Service and supported by Priority Research Centers Program through the National Research Foundation of Korea (NRF) funded by the Ministry of Education, Science and Technology (2009-0093824), Korea.

\section{References}

1. Anastasiadou, S., Papagianni, M., Ambrosiadis, I., and Koidis, P. (2008) Rapid quantifiable assessment of nutritional parameters influencing pediocin production by Pediococcus acidilactici NRRL B5627. Bioresource Technol. 99, 66466650.

2. Anthony, T., Rajesh, T., Kayalvizhi, N., and Gunasekaran, P. (2009) Influence of medium components and fermentation 
conditions on the production of bacteriocin(s) by Bacillus licheniformis AnBa9. Bioresource Technol. 100, 872-877

3. Barboza-Corona, J. E., Fuente-Salcido, N., Alva-Murillo, N., Ochoa-Zarzosa, A., and Lopez-Meza, J. E. (2009) Activity of bacteriocins synthesized by Bacillus thuringiensis against Staphylococcus aureus isolates associated to bovine mastitis. Vet. Microbiol. 138, 179-183.

4. Cheigh, C. I., Choi, H. J., Park, H., Kim, S. B., Kook, M. C., Kim, T. S., Hwang, J. K., and Pyun, Y. R. (2002) Influence of growth conditions on the production of a nisin-like bacteriocin by Lactococcus lactis subsp. lactis A164 isolated from Kimchi. J. Biotechnol. 95, 225-235.

5. Choi, H. J., Cheigh, C. I., Kim, S. B., and Pyun, Y. R. (2000) Production of a nisin-like bacteriocin by Lactococcus lactis subsp. lactis A164 isolated from Kimchi. J. Appl. Microbiol. 88, 563-571.

6. Coelho, M. L. V., Nascimento, J. S., Fagundes, P. C., Madureira, D. J., Oliveira, S. S., Brito, M. A. V. P., and Bastos, M. C. F. (2007) Activity of staphylococcal bacteriocins against Staphylococcus aureus and Streptoccus agalactiae involved in bovine mastitis. Res. Microbiol. 158, 625-630.

7. Coenye, T. and Vandamme, P. (2003) Extracting phylogenetic information from whole-genome sequencing projects: the lactic acid bacteria as a test case, Microbiology 149, 3507-3517.

8. Delgado, A., Lopez, F. N. A., Brito, D., Peres, C., Fevereiro, P., and Garrido-Fernandez, A. (2007) Optimum bacteriocin production by Lactobacillus plantarum $17.2 \mathrm{~b}$ requires absence of $\mathrm{NaCl}$ and apparently follows a mixed metabolite kinetics. J. Biotechnol. 130, 193-201.

9. He, G. Q., Kong, Q., and Ding, L. X. (2004) Response surface methodology for optimizing the fermentation medium of Clostridium butyricum. Lett. Appl. Microbiol. 39, 363368.

10. Kim, H., Eom, H. J., Lee, J. S. Han, J. S., and Han, N. S. (2004) Statistical optimization of medium composition for growth of Leuconostoc citreum. Biotechnol. Bioproc. E. 9, 278-284

11. Kim, M. H., Kong, Y. J., Baek, H., and Hyun, H. H. (2006) Optimization of culture conditions and medium composition for the production of micrococcin GO5 by Micrococcus sp. GO5. J. Biotechnol. 121, 54-61.

12. Lee, N. K., Park, Y. L., Kim, H. W., Park, Y. H., Rhim, S. L.,
Kim, J. M., Kim, J. M., Nam, H. M., Jung, S. C., and Paik, HD. (2008) Purification and characterization of lacticin NK34 produed by Lactoccous lactis NK34 against bovine mastitis. Korean J. Food Sci. Ani. Resour. 28, 457-462.

13. Li, C., Bai, J., Cai, Z., and Ouyang, F. (2002) Optimization of a cultural medium for bacteriocin production by Lactococcus lactis using response surface methodology. J. Biotechnol. 93, 27-34.

14. Liu, B. L. and Tzeng, Y. M. (1998) Optimization of growth medium for the production of spores from Bacillus thuringiensis using response surface methodology. Bioprocess Eng. 18, 413-418.

15. Miyoshi, A., Rochat, T., Gratadoux, J. J., Le Loir, Y., Oliverira, S. C., Langella, P., and Azevedo, V. (2003) Oxidative stress in Lactococcus lactis. Genet. Mol. Res. 2, 348-359.

16. Nascimento, J. S., Fagundes, P. C., Brito, M. A. V. P., Santos, K. R. N., and Bastos, M. C. F. (2005) Production of bacteriocins by coagulase-negative staphylococci involved in bovine mastitis. Vet. Microbiol. 106, 61-71.

17. Nel, H. A., Bauer, R., Vandamme, E. J., and Dicks, L. M. T. (2001) Growth optimization of Pediococcus darmnosus NCFB1832 and the influence of $\mathrm{pH}$ and nutrients on the production of pediocin PD-1. J. Appl. Microbiol. 91, 1131-1138.

18. Ochoa-Zarsoza, A., Loeza-Angeles, H., Sahrero-Cisneros, E., Villagomez-Gomez, E. Lara-Zarate, L., and Lopez-Meza, J. E. (2008) Antibacterial activity of thionin Thi2.1 from Arabidopsis thaliana expressed by bovine endothelial cells against Staphylococcus aureus isolates from bovine mastitis. Vet. Microbiol. 127, 425-430.

19. Purama, R. K. and Goyal, A. (2008) Screening and optimization of nutritional factors for higher dextransucrase production by Leuconostoc mesenteroides NRRL B-640 using statistical approach. Bioresource Technol. 99, 7108-7114

20. Verellen, T. L. J., Bruggeman, G., Reenen, C. A. V., Dicks, L. M. T., and Vandamme, E. J. (1998) Fermentation optimization of plantaricin 423, a bacteriocin produced by Lactobacillus plantarum 423. J. Ferment. Bioeng. 86, 174-179.

21. Wang, Z. W. and Liu, X. L. (2008) Medium optimization for antifungal active substances production from a newly isolated Paenibacillus sp. using surface methodology. Bioresource Technol. 99, 8245-8251.

(Received 2009.10.30/Revised 2010.2.16/Accepted 2010.2.17) 